\title{
ARTIGOS
}

\section{DISPOSITIVO DA ANTECIPAÇÃO DA ALFABETIZAÇÃO: CONDIÇÕES DE EMERGËNCIA E CONTORNOS ATUAIS}

MARIA CAROLINA DA SILVA CALDEIRA •

MARLUCY ALVES PARAÍSO

\section{RESUMO}

Este artigo discute as condições de emergência e os efeitos do dispositivo da antecipação da alfabetização, que muda a idade em que a alfabetização deve ser consolidada para o primeiro ano do ensino fundamental. Argumenta-se que historicamente foi engendrado um dispositivo que articulou diferentes discursos, enunciados científicos, leis, proposições filosóficas, jurídicas e morais que têm como efeito nas escolas a exigência de que as crianças sejam alfabetizadas no primeiro ano. A discussão sobre a maturidade, os estudos sobre a psicogênese da escrita e sobre letramento são aqui analisados como práticas discursivas que deram as condições de emergência de um dispositivo que antecipa não somente a entrada no ensino fundamental, mas também a exigência da alfabetização plena dessas crianças.

\section{LETRAMENTO • LEITURA • ESCRITA • ENSINO FUNDAMENTAL}

\section{LITERACY ANTICIPATION DEVICE: CONDITIONS FOR ITS EMERGENCE AND ITS CURRENT CONTOURS}

\section{ABSTRACT}

This article discusses the conditions for the emergence and the effects of the literacy anticipation device that changes the age at which literacy must be consolidated to the first year of elementary school. It is argued that, historically, a device was engineered that articulated different discussions, scientific statements, laws, and philosophical, legal and moral propositions that have, as their effect in the schools, the requirement that children be literate in the first year of elementary school. The discussion about maturity, the studies on the psychogenesis of writing and literacy are analyzed herein as discursive practices that provided the conditions for the emergence of a device which anticipates not only the entrance into elementary school, but also the requirement of the full literacy of these children. 


\section{DISPOSITIF DE L'ANTICIPATION DE L'ALPHABÉTISATION: LES CONDITIONS D'ÉMERGENCE ET LES CONTOURS ACTUELS}

RÉSUMÉ

Cet article discute les conditions d'émergence et les effets du dispositif de l'anticipation de l'alphabétisation, qui change l'âge à laquelle l'alphabétisation doit être consolidée pour la première année de l'enseignement fondamental. On argumente qu'historiquement a été engendré un dispositif qui a articulé des différents discours, énoncés scientifiques, lois, propositions philosophiques, juridiques et morales qui ont pour effet, dans les écoles, l'exigence que les enfants soient alphabétisés au cours de la première année. La discussion à propos de la maturité, les études sur la psychogenèse de l'écriture et sur l'alphabétisation sont analysés ici en tant que conduites discursives qui ont engendré l'émergence d'un dispositif qui anticipe non seulement l'entrée dans l'enseignement fondamental, mais aussi l'exigence de l'alphabétisation pleine de ces enfants.

LITTÉRATIE • LECTURE • ÉCRITURE・ENSEIGNEMENT PRIMAIRE

\section{DISPOSITIVO DE LA ANTICIPACIÓN DE LA ALFABETIZACIÓN: CONDICIONES DE EMERGENCIA Y CONTORNOS ACTUALES}

RESUMEN

Este artículo discute las condiciones de emergencia y los efectos del dispositivo de la anticipación de la alfabetización, que cambia la edad en que la alfabetización debe ser consolidada para el primer año de la educación básica. Se argumenta que históricamente se generó un dispositivo que articuló diferentes discursos, enunciados científicos, leyes, proposiciones filosóficas, jurídicas y morales cuyo efecto en las escuelas es la exigencia de que los niños sean alfabetizados el primer año. La discusión sobre la madurez, los estudios sobre la psicogénesis de la escritura y sobre letramiento son aquí analizados como prácticas discursivas que dieron origen a las condiciones de emergencia de un dispositivo que no sólo anticipa el ingreso en la educación básica, sino también a la exigencia de la alfabetización plena de estos niños. 
Essa lei tornou obrigatória a matrícula das crianças a partir dos seis anos de idade no ensino fundamental.

A Lei n. 11.274/2006 ampliou o ensino fundamental de oito para nove anos com início a partir dos seis anos de idade.

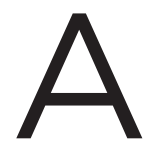

S QUESTÕES QUE ENVOLVEM O PROCESSO DE ALFABETIZAÇÃo CONSTITUEM-SE EM uma das principais polêmicas no que concerne à ampliação do ensino fundamental para nove anos. Ainda que as leis n. 11.114/2005 ${ }^{1} \mathrm{e}$ n. $11.274 / 2006^{2}$ não entrem na discussão a respeito da alfabetização, ao se antecipar o momento em que as crianças devem ingressar no ensino

\section{(a)}

Uma análise de reportagens sobre a alfabetização aos seis anos pode ser vista em Oliveira (2012).

Exemplos de blogs que defendem a antecipação da alfabetização podem ser vistos em: <http:// ensfundamental1.wordpress com/projeto-alfabetizarem-tempo-6-anos/>e <http://luecompania. blogspot.com.br/2013/02/ alfabetizar-as-criancasaos-seis-anos-e.html> Acesso em: 25 mar. 2013

\section{. fundamental, o debate sobre que lugar a alfabetização deve ocupar no primeiro ano ganhou destaque. Isso pode ser percebido em diferentes artefatos culturais, tais como reportagens, ${ }^{3}$ blogs, ${ }^{4}$ discussões acadêmicas e pesquisas educacionais, ${ }^{5}$ nas quais esse debate se evidencia.

Adiantar em um ano o início do ensino fundamental não foi uma política trivial. Afinal, essa antecipação rompe com uma ideia antiga que remete à "tradição hipocrática de se dividir a infância em três períodos: infantia, do nascimento aos 7 anos; puerícia, dos 7 aos 12 anos para meninas, e dos 7 aos 14 para meninos, e adolescentia, dos 12 ou 14 até os 21” (HEYWOOD, 2005, p. 26). Essa política também rompeu com uma tradição presente no discurso do cristianismo, no qual a idade de sete anos "é considerada como passagem para a idade da razão e das primeiras responsabilidades, influenciando o ingresso nas escolas e atividades mais sistematizadas de aprendizagem" (OLIVEIRA, 2012, p. 2). Sem falar que essa política também teve que romper com vários discursos que consideram que, até os seis anos, “as práticas pedagógicas que compõem a proposta curricular da Educação Infantil devem ter como eixos norteadores as interações e a brincadeira” (BRASIL, 2010, p. 25). 
No Brasil, ao longo do século XIX, e particularmente no século XX, um aparato jurídico foi constituído a fim de garantir a obrigatoriedade escolar, em consonância com diferentes países europeus, nos quais já havia "leis de obrigatoriedade escolar, que conferiram visibilidade social à idade da meninice (por volta dos 7 aos 14 anos) entendida como idade escolar" (GOUVEA, 2004, p. 265). É possível notar a articulação de diferentes formações discursivas - médicas, filosóficas, religiosas, jurídicas, pedagógicas - para justificar o ingresso nas atividades escolares aos sete anos. Com as leis n. 11.114/2005 e n. 11.274/2006, no entanto, essa situação se altera no Brasil, rompendo-se com diferentes discursos e tradições.

Este artigo mostra como, para produzir tal mudança, foi preciso articular um dispositivo de antecipação da alfabetização, cujas bases foram sendo construídas ao longo da história da educação brasileira. A defesa pelo direito à alfabetização, de modo específico, e à cultura escolar, de modo ampliado, é um dos elementos que contribui para a ampliação do ensino fundamental por meio da inserção de mais um ano no seu início. Além disso, fatores econômicos também pesaram nessa decisão. Estudos indicavam que havia salas de ensino fundamental ociosas nas escolas e professores/as dos anos iniciais que poderiam assumir tais turmas. Além disso, muitas redes de ensino já matriculavam as crianças de seis anos no ensino fundamental ou em classes de alfabetização (BRASIL, 2004). A entrada no ensino fundamental era também uma forma de garantir que as crianças de classe popular tivessem acesso à educação, já que esse era o nível de ensino obrigatório em nosso país. ${ }^{6}$ Um dos argumentos decisivos, porém, referia-se à ideia de que, com a entrada das crianças aos seis anos, "criam-se melhores condições para a alfabetização das crianças, sendo este considerado um dos problemas históricos da educação brasileira” (SANTOS; VIEIRA, 2006, p. 780). Com base nessas diferentes argumentações, o dispositivo de antecipação da alfabetização passou a operar ostensivamente no primeiro ano do ensino fundamental.

Dispositivo é entendido aqui como um conjunto de elementos heterogêneos, tais como "discursos, instituições, organizações arquitetônicas, decisões regulamentares, leis, medidas administrativas, enunciados científicos, proposições filosóficas, morais, filantrópicas” (FOUCAULT, 2000a, p. 244) que dispõem os indivíduos em determinadas relações de poder. Segundo Agamben (2005, p. 9), esse conceito passa a fazer parte dos estudos desenvolvidos por Foucault quando ele se dedica à discussão sobre o "governo dos homens". Assim, para explicar como nas sociedades operava o governo, Foucault recorre a elementos múltiplos, que envolvem o discursivo e o não discursivo. No caso específico do dispositivo da antecipação da alfabetização, consideramos que ele funciona para governar os/as professores/as e os/as alunos/as que ingressam n. 59 torna obrigatória a escolarização básica dos quatro aos dezessete anos a partir de 2016. 
no $1^{\circ}$ ano do ensino fundamental, para garantir a plena alfabetização de todos/as o mais cedo possível. ${ }^{7}$

A escolha por usar o termo antecipação se deve ao fato de que, historicamente no Brasil, a idade de sete anos foi considerada a adequada para o ingresso na escola de ensino fundamental e esse nível de ensino era, de modo geral, considerado responsável por garantir a alfabetização. Mesmo considerando que as classes médias e altas já vinham, há muito tempo, antecipando a alfabetização de seus/suas filhos/as, seja

Diferentes pesquisas vêm mostrando como a expansão do ensino fundamental tem feito com que o primeiro ano se centre quase que exclusivamente na alfabetização. Pansin e Marin (2011), em estudo realizado em Rondônia. mostram como a ênfase no primeiro ano recaía na alfabetização. As pesquisadoras narram a pressão sentida pelas professoras alfabetizadoras para garantir que as crianças soubessem ler e escrever ao final do ano. Correa (2011) mostra situação semelhante em escolas do interior de São Paulo. Paraíso (2014), em estudo conduzido em Belo Horizonte, evidencia como na ânsia de alfabetizar maior número possíve de alunos aos seis anos, ocorre, já nos primeiros dias de aula, todo um processo de diferenciação exclusão daqueles que não frequentaram a educação infantil. A pesquisadora afirma que, nesse contexto de ânsia voraz de garanti a alfabetização no primeiro ano do ensino fundamental, considera-se normal essa diferenciação e exclusão, porque se defende que essas crianças não têm condições mínimas para serem alfabetizadas.

Esse modo de compreender a alfabetização no primeiro ano do ensino fundamenta foi percebido na pesquisa de doutorado que subsidia este artigo. A referida pesquisa acompanhou o currículo de uma turma da rede municipal de Belo Horizonte ao longo de um ano. Ainda que documentos diferentes afirmem que a alfabetização deve ser consolidada ao final do terceiro ano do ensino fundamental, na pesquisa realizada, verificou-se que o objetivo era garantir a consolidação desse processo já ao final do primeiro ano. na educação infantil, seja em suas próprias casas, isso ainda não ocorria com grande parte da população brasileira que só frequentava a escola quando ela se tornava obrigatória. Com as leis n. 11.114/2005 e n. 11.274/2006, no entanto, houve uma antecipação, no sentido apresentado pelo dicionário Houaiss, segundo o qual antecipar significa "fazer chegar ou ocorrer antes do esperado”. O esperado era que as crianças passassem a frequentar a escola de ensino fundamental aos sete anos de idade e aí tivessem sua alfabetização consolidada. Essa expectativa "é fruto de uma construção histórica” (GOUVEA, 2004, p. 265) e não um dado natural. Neste artigo, entende-se por "consolidação da alfabetização" o momento em que as crianças são capazes de codificar e decodificar com autonomia, atribuir sentido a textos escritos e produzir escritas compreensíveis por outros/as alfabetizados/as. Ainda que haja inúmeras definições do que seja ler e escrever - que vão desde a capacidade de decodificar e codificar símbolos escritos até a reflexão crítica sobre aquilo que se lê e se escreve (BAPTISTA, 2010) -, considera-se que é o tipo de habilidade descrito anteriormente que se espera que as crianças construam até o final do ensino fundamental. ${ }^{8}$

Sendo assim, o objetivo deste artigo é mostrar como práticas discursivas presentes na história da alfabetização brasileira possibilitaram que, gradativamente, a idade de entrada no ensino fundamental fosse diminuída e a consequente antecipação da alfabetização acontecesse. O propósito aqui não é recontar toda a história da alfabetização, mas localizar, em diferentes momentos dessa história, práticas que permitem compreender as "condições de emergência" desse dispositivo. Segundo Foucault (2000b p. 23), é importante compreender como um determinado discurso aparece não pelo seu "termo final", mas pelas forças que lutaram em diversos períodos históricos para construir uma verdade. O mesmo é feito aqui ao analisar a irrupção do dispositivo da antecipação da alfabetização. Pretende-se "mostrar seu jogo, a maneira como elas [as forças] lutam umas contra as outras, ou seu combate frente a circunstâncias adversas” (FOUCAULT, 2000b, p. 23). É preciso, então, buscar suas condições de possibilidade antes do instante em que a antecipação se corporifica em forma de lei, pois anteriormente existiram disputas para garantir que ela fosse produzida como uma necessidade e, portanto, como um discurso verdadeiro. Para mostrar esse caminho, mapeamos 
os discursos que foram se estabelecendo como verdade sobre alfabetização e que conduziram a uma crescente antecipação desse processo. Consideramos, para isso, que "a verdade é deste mundo; ela é produzida nele graças a múltiplas coerções e nele produz efeitos regulamentados de poder" (FOUCAULT, 2000c, p. 12). Assim, a verdade segundo a qual as crianças devem ser alfabetizadas o quanto antes, hoje divulgada com tanta aceitação, tem uma história que pode ser reconstruída e analisada, visando ao entendimento das condições que possibilitaram sua emergência. Isso porque, no processo de desnaturalização das mais diferentes práticas, é importante compreender “como os discursos se tornaram verdadeiros, quais foram as relações de poder travadas, quais estratégias foram usadas, que outros discursos foram excluídos para que estes pudessem ser autorizados e divulgados" (PARAÍSO, 2012, p. 28).

Para tanto, o argumento aqui desenvolvido é de que proposições filosóficas, científicas, morais e jurídicas presentes em diferentes discursos divulgados nas discussões sobre "métodos de alfabetização e testes de maturidade", "psicogênese da língua escrita" e "letramento" deram a base para que o dispositivo da antecipação se consolidasse e passasse a constituir-se em uma verdade educacional de nosso tempo. Tal verdade tem tido como efeito, nas escolas, uma exigência para que as crianças sejam plenamente alfabetizadas aos seis anos, ou seja, já no primeiro ano do ensino fundamental. Com o objetivo de mostrar como se deu esse processo de construção do dispositivo, este artigo está dividido em quatro partes, nas quais são focalizados diferentes momentos da educação brasileira. O primeiro deles foi denominado "Entre métodos e testes: a idade da maturidade”. Nele, explicamos como, em parte significativa da história da alfabetização, o importante não era uma idade pré-estabelecida para iniciar a referida alfabetização, mas sim a prontidão e a maturidade da criança, que não correspondia necessariamente a uma idade cronológica. Em seguida, no item nomeado "As hipóteses que não têm idade”, analisamos como a psicogênese da língua escrita inseriu as crianças que estavam em processo de alfabetização em outras relações de poder e reorganizou o processo de aquisição da língua escrita, construindo novas bases para a sua antecipação. Por fim, no item "No mundo da escrita desde o nascimento", apresentamos como o discurso do letramento também é usado como um ponto de apoio para tal antecipação. Para concluir, evidenciamos discursos concorrentes ao dispositivo da antecipação da alfabetização, que criam tensões nas relações com a alfabetização no ensino fundamental. Para "mostrar o que já foi dito, pesquisado e significado” (PARAÍSO, 2012, p. 35) sobre alfabetização, foram utilizados livros, materiais didáticos, artigos, trabalhos e documentos produzidos em diferentes momentos históricos e que permitem traçar um mapa das condições de emergência do referido dispositivo. Além disso, ao longo dos diferentes momentos, mostramos os efeitos 
que essas práticas discursivas têm nas escolas e turmas do primeiro ano do ensino fundamental.

\section{ENTRE MÉTODOS E TESTES: A IDADE DA MATURIDADE}

Cartilhas, exercícios de prontidão, cópia, treinos ortográficos, famílias silábicas, “Ivo viu a uva”, “o boi baba”, “a baba é boa”, ${ }^{9}$ pré-livros, palavras significativas, frases contextualizadas, contos, "Eu me chamo Lili! Eu comi muito doce! Vocês gostam de doce? Eu gosto tanto de doce”! ${ }^{10}$ Para aqueles/as que vivenciaram seu processo de alfabetização no momento que aqui nomeamos como "Idade da maturidade", algumas dessas referências podem estar presentes. Elas traduzem elementos característicos do debate existente ao longo do século XX na alfabetização brasileira: a chamada "querela dos métodos" (MACIEL, 2003, p. 14), que foi gradativamente substituída pela importância dos testes de prontidão.

A primeira disputa colocava, de um lado, os/as defensores/as dos chamados "métodos sintéticos" da alfabetização, que vão “das partes para o todo" (FRADE, 2005, p. 22), ou seja, que partem da letra, do fonema ou da sílaba para proporcionar a aprendizagem da leitura. Foram assim criados os métodos alfabético, fônico e silábico, nos quais se privilegiava a aprendizagem de partes consideradas mais simples, para, posteriormente, chegar às unidades de sentido da língua (palavras, frases e textos). Do outro lado da contenda, estavam os/as defensores/as do "método analítico", que argumentavam que o "ensino da leitura deveria ser iniciado pelo ‘todo’, para depois se proceder à análise de suas partes constitutivas" (MORTATTI, 2006, p. 7). O que constituía esse todo era motivo de debate entre os/as defensores/as dos métodos analíticos: poderia ser a palavra, a sentença ou o texto.

No Brasil, a partir da década de 1880, a introdução da Cartilha maternal, do poeta português João de Deus, inspirada no método da palavração, ganha destaque. Considera-se que a Cartilha maternal e a adoção dos métodos analíticos seriam capazes de "reverter o 'atraso horroroso' e o 'sofisma do império', baseando-se em um projeto de fundação de uma civilização nos trópicos, [para a qual se] enfatiza a importância da aprendizagem da leitura” (MORTATTI, 2000, p. 45). De inspiração positivista, a argumentação daqueles que defendem esse método, segundo Mortatti (2000, p. 73), considera que "o ensino da leitura envolve necessariamente uma questão de método, apresentando-se o 'método João de

Deus' (palavração) como fase científica e definitiva nesse ensino e fator de progresso social".

A defesa da cientificidade na alfabetização ganha mais força a partir do século XX, quando testes realizados nos Estados Unidos evidenciam a potencialidade dos métodos analíticos para garantir a 
alfabetização. Esses testes chegam às escolas normais e escolas experimentais, conquistando adeptos/as entre as normalistas e suas professoras (MACIEL, 2001). Em função dessa adesão, esses métodos são até mesmo institucionalizados por governos estaduais brasileiros. É o que ocorre em São Paulo, em 1909 e 1910 (MORTATTI, 2000, p. 83), e em Minas Gerais, por meio da Reforma Francisco Campos de 1927, a partir da qual "é adotado o método global para a alfabetização de crianças" (MACIEL, 2003, p. 13). Tais definições legais vão perdendo força ao longo do tempo. Apesar da oficialização dos métodos globais, a "querela dos métodos" é marcada justamente pela oposição que se estabelece entre aqueles/as que os defendem (e que, nas primeiras décadas do século XX, conseguem estabelecer seus princípios como mais verdadeiros) e aqueles que defendem os métodos sintéticos, particularmente a silabação.

Mas o que a querela dos métodos tem a ver com a antecipação da alfabetização? Aparentemente, muito pouco, já que a idade oficial para se alfabetizar no início do século XX era sete anos. Como decreta Lourenço Filho, "idade de sete anos é a da maioridade escolar, como a de vinte e um, a da maioridade civil” (2008, p. 23, destaques do autor). Contudo, alguns princípios que serão utilizados posteriormente para dar base ao dispositivo de antecipação da alfabetização já estavam ali. É o caso dos testes padronizados que, embora sejam responsáveis pelo declínio da "querela dos métodos", são criados nesse momento histórico. Esses testes tinham como objetivo medir "a maturidade escolar e as funções psicológicas básicas correlacionadas às primeiras aprendizagens, principalmente à alfabetização" (MOLL, 1996, p. 58). Entre eles, temos: “Testes ABC, Prova das Funções Básicas; Metropolitan Reading Readiness Test-MRT; Escala de Osretzki; Teste de Marthe Vyl; Provas de Stambal e outros" (MOLL, 1996, p. 58). Na explicação do teste ABC, ${ }^{11}$ Lourenço Filho (2008, p. 15) registrava que o nível de maturidade "não apresenta coincidência rigorosa com a idade cronológica, nem com a idade mental de cada aluno, logo se percebe a importância prática de tal verificação”, pois essa maturidade é individual. Daí a necessidade de testes para saber se a criança está "madura” para a alfabetização.

A idade de maturação é definida como o momento "em que o aluno está preparado para receber a aprendizagem” (OLIVEIRA; MONTEIRO 1983, p. 41). Ela se caracteriza por um equilíbrio entre aspectos motores, mentais, verbais e sociais. Por meio dos testes, considera-se que é possível analisar "os comportamentos de ler e escrever e tentar arrolar quais são os comportamentos pré-requisitos que os facilitam ou mesmo tornam possível sua aprendizagem” (LEITE, 1984, p. 24). No caso dos Testes ABC, por exemplo, eram considerados pré-requisitos para a alfabetização: coordenação visual-motora, resistência à inversão na cópia de figuras, memorização visual, coordenação auditivo-motora, capacidade de prolação, ${ }^{12}$ resistência à ecolalia, ${ }^{13}$ memorização auditiva, índice de provas, sendo que cada prova vale de zero a três pontos, que visam a verificar as condições de maturidade de cada criança. Foram desenvolvidos por Lourenço Filho nos anos 1920 e amplamente divulgados no Brasil e no mundo. 12 Capacidade de articulação das palavras.

13

Repetição de palavras ou frases ouvidas. 
fadigabilidade, índice de atenção dirigida, vocabulário e compreensão geral (MORTATTI, 2000, p. 151).

Com base nos resultados das crianças nos testes, determinavase em quanto tempo ela poderia se alfabetizar. ${ }^{14}$ Diante disso, Lourenço Filho (2008, p. 16) afirmava que aquilo que importava saber era "qual o momento em que esta criança, João, Benedito ou Maria, está apta para receber o ensino da leitura, com melhor aproveitamento, ou a que regime deverá ser sujeita, para que isso possa ser obtido", ou seja, não adianta determinar uma idade específica para alfabetizar. É preciso saber em que momento cada criança pode receber essa aprendizagem. O fato de que nem todas as crianças de uma mesma idade têm a mesma maturidade era considerado um problema para as escolas. Por isso, dizia-se que na tentativa de "minimizar o problema tem sido adotado há alguns anos nas escolas da rede oficial: o chamado período preparatório" (LEITE, 1984, p. 12). Ele é "a fase em que o aluno é preparado para a aprendizagem da leitura e da escrita. Essa fase é bastante flexível, sua duração dependerá exclusivamente do aluno" (OLIVEIRA; MONTEIRO 1983, p. 22).

Percebem-se aí algumas condições de possibilidades para que o dispositivo da antecipação da alfabetização opere. Não se trata, ainda, de uma definição geral da antecipação, mas de uma determinação individual: se a criança for madura, ela pode ir para uma "turma forte", o que garantirá que ela se alfabetize mais rapidamente. Se ela não for madura, precisará de um "longo período de preparação". Um enunciado considerado científico na época é acionado para que um tipo de adiantamento ou adiamento das práticas de alfabetização seja efetuado. Nas práticas de algumas escolas, como aponta Smolka (1988, p. 40), estar em uma "turma fraca" significava "aparentemente que as crianças estavam sendo 'preparadas para aprender a ler e a escrever', mas, de fato, implicitamente, o que ocorria era a negação do conhecimento a quem ainda não o possuía”. A despeito dessas críticas, pode-se notar que os testes padronizados, decorrentes dos métodos de alfabetização, deram base para uma antecipação ou um adiamento individual da alfabetização. A necessidade, porém, de adiantar a alfabetização se tornará mais forte em dois outros momentos históricos: aqueles influenciados pela psicogênese da língua escrita e pelos estudos sobre letramento.

Os resultados eram os equintes: se o/a aluno/a conseguia de 18 a 24 pontos, aprenderia a ler em seis meses. Se fizesse de 11 a 17 pontos, aprenderia em um ano; de oito a dez pontos, necessitaria de cuidados especiais que, se fossem providos garantiriam aprendizado em um ano. Com menos de sete pontos, o aluno seria imaturo e precisaria de uma longa fase preparatóri (LOURENÇO FILHO, 2008).

\section{AS HIPÓTESES QUE NÃO TÊM IDADE}

Escrita espontânea, desenvolvimento cognitivo, escrita como representação, processo de acomodação e assimilação, silábico, silábico-alfabético, alfabético: essas são algumas das palavras comumente associadas àquilo que no Brasil foi divulgado como "psicogênese da língua escrita" e que tem como principal expoente a argentina Emilia Ferreiro. O livro que inaugura essa perspectiva no Brasil apresenta como seu objetivo 
"tentar uma explicação dos processos e das formas mediante as quais a criança consegue aprender a ler e a escrever" (FERREIRO; TEBEROSKY, 1985, p. 17). Por meio de pesquisas realizadas por dois anos com crianças de quatro a seis anos, as autoras demonstram que processos cognitivos estão na base da aprendizagem da leitura e da escrita. Partindo de princípios da psicologia genética piagetiana, foi realizada uma série de testes com crianças, nos quais tentam compreender como elas conceptualizam a escrita. Os resultados serviram para que fossem feitas fortes críticas aos métodos de alfabetização e aos testes de maturação.

No que concerne aos métodos, tanto aqueles que se enquadram na "marcha sintética" como os que se apresentam na "marcha analítica” são considerados problemáticos nessa perspectiva por partirem de um pressuposto errado. Nos primeiros, “o processo de aprendizagem da leitura é visto, simplesmente, como uma associação entre respostas sonoras e estímulos gráficos” (FERREIRO; TEBEROSKY, 1985, p. 22). Nos métodos analíticos, a aprendizagem é entendida como "uma tarefa fundamentalmente visual” (FERREIRO, TEBEROSKY, 1985, p. 22). Para Ferreiro e Teberosky (1985), o erro das duas perspectivas é que estas ignoram o sujeito da aprendizagem, sua competência linguística e suas capacidades cognoscitivas. Além disso, essas perspectivas concebem a língua escrita como transcrição da língua falada (FERREIRO, 1985), enquanto, na perspectiva da psicogênese, ela é um sistema de representação. Sendo assim, a aprendizagem da escrita é "conceitual e não a aquisição de uma técnica, ou seja, [é] um processo interno e individual de compreensão do modo de construção desse sistema, sem separação entre leitura e escrita e mediante a interação do sujeito com o objeto de conhecimento" (MORTATTI, 2000, p. 266). Aí está o motivo do erro dos testes de prontidão, que estão preocupados em medir as capacidades infantis "relacionadas à percepção e à motricidade, [...] à presença maior ou menor de capacidades importantes para a realização gráfica de traços sobre o papel” (AZENHA, 2006, p. 51), em vez de desenvolver as capacidades conceituais necessárias à alfabetização.

Em função dos problemas percebidos nas perspectivas anteriores, a psicogênese marca seu distanciamento em relação aos métodos e aos testes, quando as autoras afirmam: "não pretendemos propor uma nova metodologia de aprendizagem nem uma nova classificação dos transtornos da aprendizagem" (FERREIRO; TEBEROSKY, 1985, p. 17). O que pretendem é mostrar como as crianças entendem a escrita. Por meio de diferentes testes, realizados com crianças pertencentes a grupos sociais diversos, defendem que "a escrita infantil segue uma evolução surpreendentemente regular, através de diversos meios culturais, de diversas situações educativas, de diversas línguas” (FERREIRO, 1985, p. 10).

Segundo essa perspectiva, essa evolução se iniciaria com um primeiro grande período, no qual as crianças aprendem a distinguir entre 
o modo de representação icônico (desenhos) e o não icônico (FERREIRO, 1985). Em seguida, são criados mecanismos progressivos de controle sobre as variações que fazem com que escritas sejam diferentes. Depois, ocorre o processo de fonetização da escrita, quando as crianças compreendem que a língua escrita é uma representação (arbitrária) dos sons (FERREIRO; TEBEROSKY, 1985). De modo geral, as hipóteses infantis sobre a língua são nomeadas como pré-silábica (período anterior à fonetização), silábica (na qual a criança usa uma sílaba para cada letra), silábica -alfabética (quando há alternância entre usar uma letra para cada sílaba e sílabas inteiras) e alfabética (momento em que a escrita torna-se convencional) (FERREIRO, 1985). Cabe registrar que, a despeito do que propõem as autoras, em alguns momentos, como resultado da “combinação dos métodos tradicionais com as implicações pedagógicas das pesquisas de Ferreiro" (MORTATTI, 2000, p. 286), as crianças passaram a ser agrupadas, durante as práticas de alfabetização nas escolas, em pré-silábicas, silábicas, alfabéticas, em um tipo de adaptação da classificação feita pelos testes de prontidão. Isso foi observado na pesquisa realizada em uma escola de Belo Horizonte durante o ano de 2013, em que operava o dispositivo de antecipação da alfabetização. Nela, as crianças eram assim classificadas. Aquelas que, após o mês de setembro, ainda não estivessem silábicas eram encaminhadas para "aulas de reforço", que ocorriam durante os momentos de Educação Física. Como efeito do dispositivo de antecipação da alfabetização, criava-se um espaço de confinamento (POPKEWITZ, 2013), no qual as crianças consideradas “atrasadas” no processo de desenvolvimento precisam ficar para se alfabetizar até o final do primeiro ano do ensino fundamental.

Percebe-se, assim, como esse modo de classificar as construções que as crianças fazem sobre a escrita inspirou algumas propostas pedagógicas ou didáticas. Embora a psicogênese da escrita se afaste dos métodos de alfabetização e afirme inúmeras vezes que seu objetivo não é traçar metodologias, em várias das publicações por ela inspiradas, podem-se perceber elementos de orientações didático-pedagógicas. A importância dessas propostas no contexto da psicogênese é notada em levantamento realizado por Soares e Maciel (2000, p. 16) em teses e dissertações sobre alfabetização defendidas no Brasil nos anos 1980. Nelas, as propostas didáticas de inspiração psicogenética são o segundo tema mais pesquisado, ficando atrás apenas da discussão sobre o que causa o fracasso escolar na alfabetização. Tal importância pode ser evidenciada também quando se afirma que a pesquisa que deu base a essa teorização tem "como fim último o de contribuir na solução dos problemas de aprendizagem da lectoescrita na América Latina e o de evitar que o sistema escolar continue produzindo futuros analfabetos" (FERREIRO; TEBEROSKY, 1985, p. 35). Ou, ainda, quando se listam características de propostas “alternativas” de alfabetização (FERREIRO, 1992). Nesse 
sentido, o distanciamento que se quer em relação aos métodos - embora faça sentido em termos de pressupostos nos quais as duas vertentes se baseiam - é arbitrário, pois o objetivo da psicogênese é ainda intervir naquilo que acontece em sala de aula, com vistas a atingir determinadas finalidades, entre as quais a inserção das crianças nas práticas de leitura e escrita.

Se os estudos sobre a maturação defendiam a individualidade do aprendizado, a perspectiva psicogenética argumenta em prol da homogeneidade: as crianças passam pelo mesmo processo de aprendizagem da língua. Ainda que se pretenda trazer para as práticas de alfabetização "uma criança que procura ativamente compreender a natureza da linguagem que se fala à sua volta, e que, tratando de compreendê-la, formula hipóteses, busca regularidades, coloca à prova suas antecipações e cria sua própria gramática” (FERREIRO; TEBEROSKY, 1985, p. 24), o que se tem é uma visão genérica de criança, que passa pelas mesmas etapas, independente de sua cultura, classe social, língua, modos de vida.

Para defender essa "homogeneidade do aprendizado infantil", as autoras baseiam-se em testes, explicitam o método utilizado, discutem aspectos teóricos e trazem muita evidência empírica dos resultados encontrados. A fim de garantir a veracidade de seu discurso, elas se apoiam "em um dos mais poderosos regimes de verdade de nossa época, a Ciência” (MEYER, 2012, p. 54). Se pensarmos, conforme sugere Foucault (2000c), na articulação do discurso científico com relações de poder, é importante refletirmos: não sobre "o poder que age do exterior sobre a ciência, mas que efeitos de poder circulam entre os enunciados científicos; qual é seu regime interior de poder; como e por que em certos momentos ele se modifica de forma global" (FOUCAULT, 2000c, p. 4). Isso significa que é necessário analisar o que um discurso que se apoia nas ciências como a psicogênese produz na educação.

Uma primeira produção evidente refere-se ao efeito de verdade que esse discurso tem e que faz com que ele seja considerado "um marco divisor na história da alfabetização” (WEISZ, 1999, p. vii). Ao trazer a cientificidade para a alfabetização, esse discurso encontra muito mais facilidade para se consolidar como verdade. Mas isso não se fez de forma tranquila. Como vimos, foi preciso desqualificar outros conhecimentos, tais como o dos métodos e o dos testes de maturação, considerando-os como menos científicos ou como "um exemplo de pseudotecnicismo" (FERREIRO, 1992, p. 39). Por isso é que são trazidos dados estatísticos para mostrar que os exercícios de prontidão "se concentram precisamente no que é mais fácil de adquirir” (FERREIRO, 1992, p. 43).

Outro efeito desse discurso pode ser sentido na produção acadêmica brasileira. Se, até os anos 1980, a maior parte das pesquisas desenvolvidas no Brasil focava questões de método e prontidão, há uma queda gradativa no interesse por essas temáticas. Tal fenômeno é explicado 
por dois motivos. O primeiro é que "o reiterado fracasso em alfabetização, no Brasil, vem colocando os tradicionais métodos sob suspeita” (SOARES, 1991, p. 21). Aliado a isso, as pesquisas sobre a psicogênese - "responsáveis por uma nova concepção de alfabetização" (SOARES, 1991, p. 23) - também fazem com que o interesse por esses temas se reduza de maneira significativa.

Um terceiro efeito refere-se às bases que serão utilizadas para a antecipação da alfabetização. Esse efeito é, em alguns momentos, bastante sutil. Pode-se percebê-lo quando se afirma que, “aos 6 anos, a criança já possui toda uma série de concepções sobre a escrita, cuja gênese é preciso procurar em idades mais precoces" (FERREIRO; TEBEROSKY, 1985, p. 40), ou seja, divulga-se aí que, desde antes dos seis anos, a criança já está envolvida no processo de aquisição da língua escrita. É possível notá-lo também quando se indica que "a criança de classe média já está, em geral, no final do processo de alfabetização quando chega à escola regular" (WEISZ, 1999, p. viii). Daí infere-se que ela iniciou seu processo de alfabetização bem antes de chegar à escola, porque desde antes estava refletindo sobre a escrita. Esse processo pode, então, ser iniciado anteriormente para todas as crianças na própria instituição escolar. Em outros momentos, porém, não há sutilezas ao se demandar que as crianças estejam antes na escola para serem alfabetizadas. Isso ocorre quando é feita uma comparação explícita entre Brasil e outros países: "Na maioria dos países latino-americanos, as crianças ingressam na escola de $1^{\circ}$ grau aos 6 anos. Seria interessante perguntar-se por que o Brasil mantém sete anos como idade de ingresso" (FERREIRO, 1992, p. 36).

A crítica à idade de ingresso no ensino fundamental no Brasil é um dos modos de se constituírem as crianças de seis anos como sujeitos que têm direito ao ingresso nesse nível de ensino. Se, em outros países, a idade de ingresso no ensino fundamental é a de seis anos, causa estranheza aos/às defensores/as da psicogênese que no Brasil seja diferente. Isso é apresentado como a negação de um direito a essas crianças. Assim, as proposições científicas da psicogênese da língua escrita (que mostram como a criança pode aprender a ler antes dos sete anos) se unem às proposições morais (que afirmam ser direito infantil ir para a escola de ensino fundamental aos seis anos) para dar base ao dispositivo de antecipação da alfabetização. Nesse sentido, a linguagem escrita é apresentada como um direito ao qual as crianças devem "aceder como forma de garantir sua inclusão na sociedade contemporânea” (BAPTISTA, 2010, p. 107).

Essa construção do direito infantil à língua escrita como mecanismo essencial para a construção do dispositivo de antecipação da alfabetização é feita ainda por classe social. Nos anos 1980, a discussão sobre alfabetizar ou não aos seis anos se dava no último ano da educação infantil e não no primeiro ano do ensino fundamental, como ocorre na atualidade. Kramer e Abramovay (1985) mostram como essa 
era uma questão polêmica nas escolas de educação infantil públicas. Porém, para as escolas da rede particular, "esta não é sequer uma questão. Na rede privada, sempre se alfabetizou na educação infantil”" (KRAMER; ABRAMOVAY, 1985, p. 104). A partir dessa constatação, as autoras questionam se "a pré-escola dirigida às classes populares que nega a possibilidade de alfabetização não se constitui em mais um mecanismo de reforço à desigualdade" (KRAMER; ABRAMOVAY, 1985, p. 104). Diante disso, defende-se a necessidade de garantir a alfabetização o quanto antes, como uma forma de promoção da igualdade de oportunidades educacionais. Portanto, para a constituição do dispositivo de antecipação da alfabetização, é preciso construir a alfabetização como direito e, ao mesmo tempo, construir as crianças de seis anos como os sujeitos que devem ter esse direito garantido. Butler (2003), referindose ao feminismo, afirma que "os sistemas jurídicos de poder produzem os sujeitos que subsequentemente passam a representar" (p. 18, grifos no original). Aparentemente, o mesmo ocorre no processo de inserção das crianças de seis anos no ensino fundamental, com vistas a garantir sua alfabetização, já que todo um aparato discursivo é acionado para produzir as crianças de seis anos como seus sujeitos de direito. Dessa forma, por meio do discurso da psicogênese articulado à questão do direito da criança à alfabetização para promover a igualdade social, produz-se e divulga-se a compreensão de que a alfabetização não tem uma idade pré-definida e pode ser iniciada antes dos sete anos.

\section{NO MUNDO DA ESCRITA DESDE O NASCIMENTO}

Práticas significativas de leitura e escrita, inserção da criança na cultura escrita, sociedade letrada, diferentes gêneros textuais, literatura infantil, textos significativos, escritas coletivas, contato com diferentes suportes textuais desde cedo: esses são alguns dos elementos que caracterizam as práticas inspiradas na perspectiva do letramento, terceira prática discursiva usada para dar base à alfabetização antecipada. Há uma história contada e recontada em vários textos sobre o letramento acerca do surgimento desse termo (SOARES, 2003b). Essa história se inicia com a percepção, nos países de língua inglesa (sobretudo na Inglaterra), de que o termo alfabetização não dava conta de explicar o fenômeno vivido por aquelas pessoas que, mesmo sabendo ler e escrever, não se envolviam nas práticas sociais de uso da escrita. Tendo como princípio a compreensão de que "novas palavras são criadas (ou a velhas palavras se dá um novo sentido) quando emergem novos fatos, novas idéias, novas maneiras de compreender os fenômenos" (SOARES, 1996, p. 83-84), o termo literacy foi cunhado para explicar esse outro modo de se relacionar com a escrita nas sociedades grafocêntricas. A história prossegue com a explicação de que a palavra aparece pela primeira vez no Brasil em obra 
de Mary Kato (1986). Tfouni (1988), por sua vez, traz uma primeira definição do termo, distinguindo-o de alfabetização. Em 1995, letramento aparece como título de livro (KLEIMAN, 1995), evidência de sua rápida proliferação no campo acadêmico educacional brasileiro.

Se realizarmos uma inversão no modo de compreender a linguagem, deixando de entendê-la como "elo natural ou correspondência divina entre as palavras e as coisas” (CORAZZA, 2000, p. 90), para compreendê-la em seu caráter construcionista, poderemos analisar a história do termo letramento de outra forma. Assim, quando se toma como base a primeira visão, podemos afirmar que novas palavras são criadas para explicar fenômenos que antes não existiam. Tendo como princípio o que se propõe na segunda vertente, compreendemos que os novos fenômenos surgem com base na criação de discursos, já que "o discurso produz sistematicamente os objetos de que ele fala” (FOUCAULT, 1972, p. 174). O uso da palavra letramento tem, portanto, o efeito de construir uma nova demanda para a educação brasileira: a ideia de que não basta "o domínio da tecnologia da escrita (o sistema alfabético e ortográfico), que se obtém por meio do processo de alfabetização”; é preciso também garantir “o domínio de competências de uso dessa tecnologia (saber ler e escrever em diferentes situações e contextos), que se obtém por meio do processo de letramento" (MACIEL; LÚCIO, 2008, p. 14).

A presença do termo no discurso do campo educacional no Brasil também trouxe uma multiplicação de sentidos para o que significa letramento. Dessa forma, letramento aparece em um momento como "exercício efetivo e competente da tecnologia da escrita” (SOARES, 2003a, p. 91). Em outro, como "um conjunto de práticas sociais que usam a escrita, enquanto sistema simbólico e enquanto tecnologia, em contextos específicos, para objetivos específicos" (KLEIMAN, 1995, p. 19). Pode-se definir letramento, também, como um conceito que "focaliza os aspectos sócio-históricos da aquisição de um sistema escrito por uma sociedade" (TFOUNI, 1988, p. 16). Letramento pode ser usado para se referir a outras áreas que não a de linguagem escrita. Nesse sentido, surgem expressões como letramento digital, letramento matemático (ou numeramento), letramento geográfico, letramento artístico, letramento científico, letramento musical, entre outros (CERUTTI-RIZZATTI, 2012, p. 293). Há, ainda, a definição de letramento como um "contraponto com o conceito de alfabetização" (SOARES, 2010, p. 60). A alfabetização designa "uma aprendizagem inicial - aquisição da leitura” (SOARES, 2010, p. 61); já o letramento indica a possibilidade de fazer uso dessa tecnologia nas variadas práticas sociais que o exigem (SOARES, 1996).

Quanto a esse último aspecto, estabelece-se uma polêmica entre os/as defensores/as da psicogênese e aqueles/as que se apropriam do termo letramento. Ferreiro (1992) afirma que é necessário "restituir à língua escrita seu caráter de objeto social” (FERREIRO, 1992, p. 44), ou seja, é 
preciso ensinar a escrita e a leitura estimulando o contato da criança com a língua escrita, nos mais variados contextos. Por causa disso, não há necessidade de cunhar um novo termo que afirme a importância do uso social da língua, já que essa ideia está implícita no conceito de alfabetização. Weisz (2012, p. 37) afirma que "encarar a aprendizagem do sistema de escrita como uma etapa técnica e independente do ingresso à cultura letrada é um equívoco”.

Na contramão dessas ideias, Soares (2000, p. 5) defende que "é um risco o que se vinha fazendo, ou se vem fazendo, repetindo-se que alfabetização não é apenas ensinar a ler e a escrever, desmerecendo assim, de certa forma, a importância de ensinar a ler e a escrever”. Essa autora argumenta a favor da necessidade da especificidade de cada um dos termos, a fim de garantir que os dois processos (a codificação e decodificação em língua escrita e os usos sociais da mesma) se efetivem. Por isso, argumenta que "alfabetização e letramento são processos diferentes, mas indissociáveis” (SOARES, 2010, p. 61). De certo modo, pode-se dizer que essa vertente ganhou status de verdade na contemporaneidade, sobretudo se avaliarmos seus efeitos em termos de políticas - como a que ampliou o ensino fundamental para nove anos e que distingue alfabetização e letramento - e materiais didáticos - como aqueles avaliados pelo Programa Nacional do Livro Didático - PNLD.

Independente de qual seja a noção de letramento utilizada, há um aspecto comum às diversas acepções que é importante para o entendimento da emergência do dispositivo da antecipação da alfabetização no Brasil. Trata-se do valor que a escrita tem na vida cotidiana. Nesses estudos, afirma-se que vivemos em sociedades "grafocêntricas, isto é, sociedades organizadas em torno de um sistema de escrita em que esta, sobretudo por meio do texto escrito e impresso, assume importância central na vida das pessoas" (MORTATTI, 2004, p. 94). A cultura escrita organiza diferentes aspectos do cotidiano dos indivíduos. Por isso, afirma-se que viver em uma sociedade grafocêntrica "significa estar submetido à ordem da escrita” (BAPTISTA, 2009, p. 20).

Essa compreensão é importante para o dispositivo da antecipação da alfabetização no Brasil, pois, a partir do entendimento de que vivemos numa sociedade grafocêntrica, constrói-se uma argumentação segundo a qual as crianças estão, desde o seu nascimento, imersas no mundo da escrita. Isso significa que as crianças são entendidas como membros efetivos da sociedade grafocêntrica, o que implica que "devemos ter em conta não apenas que a linguagem escrita está presente no cotidiano desses sujeitos, mas também, e, sobretudo, que ela confere um significado distinto às suas práticas sociais” (BAPTISTA, 2009, p. 20). Em função de sua inserção na cultura escrita, argumenta-se que as crianças “desde muito cedo manifestam um grande interesse pela leitura e pela escrita, ao tentar compreender seus significados e imitar o gesto 
dos adultos escrevendo" (BRASIL, 2004, p. 21). Defende-se aí que, tendo em vista que "a cultura letrada faz parte do nosso cotidiano, ainda que se apresente com nuances específicas para segmentos diferenciados da população, entendemos que a leitura e a escrita também interessam às crianças, incluindo as menores de seis anos" (BRANDÃO; ROSA, 2010, p. 7). Assim, a noção de letramento e os discursos que a "inventaram" servem para justificar que as crianças sejam inseridas o quanto antes em práticas formalizadas de aprendizagem e de uso da leitura e da escrita, já que elas fazem isso cotidianamente. Antecipar o processo de alfabetização seria, portanto, nesse discurso, apenas uma forma de sistematizar esse processo e garanti-lo para as crianças que têm menos oportunidades de fazer isso em seu meio social.

Com tudo isso, as condições para o dispositivo de antecipação da alfabetização operar estavam dadas. Ele é operado por meio de discursos, políticas, leis, normas, regras e uma variedade de materiais que, em seu conjunto, antecipam a alfabetização plena para muitas crianças que antes se alfabetizavam aos sete anos de idade. Na pesquisa realizada na escola e que subsidia este artigo, os efeitos do discurso do letramento se faziam presentes para garantir que as crianças não apenas aprendessem a codificar e decodificar, mas também se inserissem em práticas sociais de leitura e escrita. Assim, uma variedade de textos era trabalhada em sala de aula, pois se considerava que era preciso ensinar os/as alunos/as de seis anos "a debater o texto, fazer algumas perguntas sobre o texto, trabalhar a interpretação do texto" (Entrevista com a docente, 16/05/2013). Por essa razão, muitas práticas sistematizadas de interpretação de textos estavam presentes no currículo investigado, antecipando saberes que comumente não eram trabalhados no primeiro ano do ensino fundamental, com vistas a garantir que as crianças estivessem cada vez mais inseridas na cultura escrita. Antecipava-se, assim, não apenas a codificação e a decodificação, mas também práticas de letramento escolar, deixando de lado outros saberes e fazendo com que aqueles relativos à leitura e escrita tivessem centralidade no primeiro ano.

\section{CONSIDERAÇÕES FINAIS}

O dispositivo de antecipação da alfabetização no Brasil teve a legislação de ampliação do ensino fundamental como um dos elementos que contribui para sua operacionalização nas escolas brasileiras. Ainda que não se explicite, nessa legislação, a necessidade da alfabetização aos seis anos, variadas pesquisas (PARAÍSO, 2014; CORREA, 2011; DORNELLES, 2011) evidenciam como, em turmas de seis anos, as práticas de alfabetização e letramento ocupam parte central do currículo, criando exclusões para aqueles/as que não se alfabetizem nesse período. Porém, embora esse dispositivo esteja em plena operacionalização na educação 
brasileira contemporânea, isso não se dá sem lutas e conflitos. No processo de análise de como um dispositivo funciona, é importante compreender "quais foram as relações de poder travadas, quais estratégias foram usadas, que outros discursos foram excluídos para que estes pudessem ser autorizados e divulgados" (PARAÍSO, 2012, p. 28). No caso da alfabetização, há discursos dissonantes em relação à inserção das crianças de seis anos nas práticas alfabetizadoras que, mesmo não sendo capazes de engendrar um dispositivo, criam tensões e abrem possibilidades diversas para as práticas pedagógicas com crianças de seis anos.

Alguns exemplos de vozes dissonantes aparecem esporadicamente na mídia, na qual especialistas são convocados/as para mostrar que a criança de seis anos ainda não está madura para essas aprendizagens, ou que outras linguagens devem ser estimuladas antes do processo de alfabetização. ${ }^{15}$ Pedagogos/as, neurologistas e psicólogos/as são chamados para mostrar os problemas que essa aceleração pode causar. A análise dos argumentos apontados por eles/as leva a duas vertentes principais para defender a não antecipação da alfabetização para antes dos seis anos. A primeira, vinda sobretudo da psicologia e da neurologia, aponta para a maturidade infantil, que se desenvolve prioritariamente no decorrer dos seis anos de idade. A segunda argumenta em prol do direito da criança de ter acesso a múltiplas linguagens antes de entrar no mundo da escrita.

A questão das múltiplas linguagens, e particularmente da linguagem da brincadeira, aparece como um forte contraponto à defesa da antecipação da alfabetização. Ela está presente em propostas que defendem que a educação infantil é o tempo de incentivar as múltiplas linguagens (EDWARDS; GANDINI; FORMAN, 1999). Nesse caso, afirma-se que a criança possui “cem linguagens”, mas que a alfabetização lhe rouba as outras noventa e nove (MALAGUZZI, 1999, p. 11). Está presente também na defesa que se faz do direito à brincadeira. Esta é entendida como "uma forma específica de atividade infantil, que se diferencia do trabalho produtivo por ser uma representação" (KISHIMOTO et al., 2011, p. 198). Assim, defende-se que é primordial permitir que as crianças brinquem para se desenvolver e, gradativamente, sejam inseridas na cultura escrita.

De modo geral, contudo, o que se percebe é que tanto o discurso das múltiplas linguagens como o discurso das brincadeiras acabam se inserindo na discussão acerca da alfabetização. Assim, defende-se que a alfabetização pode ser promovida por meio de "atividades e jogos que estimulam a análise fonológica” (BRANDÃO; LEAL, 2010, p. 26). Busca-se também entender "como as crianças se apropriam, manipulam e pensam sobre a língua enquanto brincam” (LEAL; SILVA, 2010, p. 57). Enfatiza-se, ainda, a necessidade de um letramento multimodal, no qual as crianças tenham acesso às múltiplas linguagens a fim de se alfabetizar (KISHIMOTO, 2010, p. 147).

Disponivel em: <http:// veja.abril.com.br/noticia/ educacao/cursar-a-la-serieantes-dos-6-anos-nao-ebom-dizem-especialistas>. Acesso em: 15 out. 2012. 
Indo em outra direção, há discursos que se opõem explicitamente à alfabetização antes dos sete anos de idade. É o caso da pedagogia Waldorf, proposta pedagógica criada em 1919, na Alemanha, por Rudolf Steiner, e que defende que o processo de desenvolvimento humano se dá em períodos de sete anos - os setênios (PINTO, 2009). No primeiro setênio (zero a sete anos), a criança "emprega todas as suas energias para o desenvolvimento do seu físico” (BRASIL, 2011, p. 5). Nesse sentido, as crianças de zero a sete anos que frequentam escolas inspiradas nessa pedagogia são matriculadas no “jardim de infância”, etapa na qual não há qualquer preocupação com a alfabetização. Um dos saberes divulgados por essa pedagogia refere-se ao fato de que a "alfabetização só deve ser iniciada após a criança ter completado sete anos de idade, o que chega até mesmo a contrariar a legislação vigente” (PINTO, 2009, p. 17). Por essa razão, há uma disputa no campo da alfabetização, que se estabelece inclusive legalmente, entre as escolas Waldorf e os discursos vinculados à antecipação da alfabetização. Discursos distintos que envolvem as crianças menores de sete anos entram em conflito e criam práticas distintas. Até o momento, o impasse não está definido, mas tem-se garantido que as escolas Waldorf possam desenvolver suas práticas de acordo com o saber baseado nos setênios e que define que o momento para a alfabetização é após os sete anos. ${ }^{16}$ Esse fato mostra como o dispositivo da antecipação da alfabetização não é unânime e se constitui em objeto de contendas e embates no campo educacional contemporâneo.

A disputa jurídica é uma das práticas criadas por esse dispositivo, que abarca tanto aqueles/as que não querem seguir essa lógica, como outros/as que pretendem antecipar ainda mais o processo de alfabetização. É o que ocorre com as diferentes ações impetradas no ministério público para que crianças com seis anos incompletos possam ser matriculadas no primeiro ano (OLIVEIRA, 2012). As querelas judiciais mostram que outra formação discursiva - a jurídica - vem sendo acionada para discutir a presença das crianças de seis anos no ensino fundamental.

É por meio dessas e de outras estratégias que o dispositivo da antecipação da alfabetização prolifera em diferentes espaços. Buscando em diferentes elementos as bases para se sustentar, esse dispositivo utiliza variados saberes, conhecimentos, discursos e proposições para se Para maiores informações sobre o processo jurídico envolvendo as escolas Waldorf, a legislação brasileira que defende a ampliação do ensino fundamental para nove anos e a matrícula das crianças de seis anos no ensino fundamental, confira o site: <http://www federacaoescolaswaldorf org.br/Noticias. php?id=1> Acesso em: 12 jan. 2015 constituir como verdade na atualidade. Ele produz múltiplas práticas, aciona e cria saberes particulares e engendra as crianças em relações de poder.

Na turma pesquisada no estudo que dá base a este artigo, era visível como esse dispositivo atuava, inserindo crianças e professoras em relações de poder que visavam à alfabetização. Esse dispositivo tinha efeitos sobre o currículo, fazendo com que certos saberes e conhecimentos fossem privilegiados, enquanto outros eram subordinados. Assim, era evidente como atividades vinculadas à alfabetização ocupavam a 
maior parte do tempo e tinham o maior espaço no currículo. Parlendas, ditados, listas de palavras, trabalho com sílabas, atividades de completar, cruzadinhas, interpretações de textos diversos, escuta de histórias com reescrita eram algumas das práticas operacionalizadas pelo dispositivo de antecipação da alfabetização. Além disso, as atividades de outras disciplinas muitas vezes acionavam mais aspectos relativos à alfabetização do que propriamente aos saberes dessas disciplinas escolares. Isso é perceptível quando, em uma atividade de Geografia, a docente diz que “isso mais parece alfabetização do que Geografia, né” (Diário de campo, 03/08/2013). Também é perceptível que saberes relativos à brincadeira e à ludicidade perdiam espaço nesse currículo para garantir que a alfabetização se efetivasse.

O caráter construído desse dispositivo mostra como ele foi montado peça por peça ao longo do tempo até se conformar com as características com as quais é divulgada e institucionalizada hoje. Mostrar como o dispositivo de antecipação da alfabetização se constituiu é importante para problematizar seus efeitos na atualidade. Afinal, se ele foi montado dessa maneira, é possível pensar em estratégias de “desmontagem” para produzir outros efeitos e sentidos para a alfabetização e a escolarização das crianças de seis anos.

\section{REFERÊNCIAS}

AGAMBEN, Giorgio. O que é um dispositivo. Outra travessia, Florianópolis, n. 5, p. 9-16,

$2^{\circ}$ semestre de 2005 .

AZENHA, Maria da Graça. Construtivismo: de Piaget a Emilia Ferreiro. 8. ed. São Paulo: Ática, 2006.

BAPTISTA, Monica. Alfabetização e letramento em classes de crianças menores de sete anos. In: DALBEN, Angela; DINIZ, Júlio; LEAL, Leiva; SANTOS, Lucíola (Org.). Convergências e tensões no campo da formação e do trabalho docente: currículo, ensino de educação física; ensino de geografia; ensino de história; escola, família e comunidade. Belo Horizonte: Autêntica, 2010. p. 95-110.

BAPTISTA, Monica et al. A criança de 6 anos, a linguagem escrita e o ensino fundamental de nove anos: orientações para o trabalho com a linguagem escrita em turmas de crianças de seis anos de idade. Brasília, DF: MEC, 2009.

BRANDÃO, Ana; LEAL, Telma. Alfabetizar e letrar na educação infantil: o que isso significa? In: BRANDÃO, Ana; ROSA, Ester. Ler e escrever na educação infantil. Belo Horizonte: Autêntica, 2010. p. 13-32.

BRANDÃO, Ana; ROSA, Ester. Apresentação. In: BRANDÃO, Ana; ROSA, Ester. Ler e escrever na educação infantil. Belo Horizonte: Autêntica, 2010. p. 7-12.

BRASIL. Ministério da Educação. Ensino fundamental de nove anos: orientações gerais. Brasília: MEC/SEB, 2004.

BRASIL. Ministério da Educação. Diretrizes curriculares nacionais para a educação infantil. Brasília: MEC/SEB, 2010.

BRASIL. Estudo apresentado pelo conselheiro Francisco Aparecido Cordão, em 08/12/2011, à Câmara de Educação Básica do Conselho Nacional de Educação a propósito de consulta da Federação das Escolas Waldorf no Brasil inicial de alunos no ensino fundamental de nove anos. Brasília: MEC, 2011.

BUTLER, Judith. Problemas de gênero: feminismo e subversão da identidade. Rio de Janeiro: Civilização Brasileira, 2003. 
CERUTTI-RIZZATTI, Mary. Letramento: uma discussão sobre implicações de fronteiras conceituais. Educação e Sociedade, v. 33, n. 18, p. 291-305, jan./mar. 2012.

CORAZZA, Sandra. O que faz gaguejar a linguagem da escola. In: CANDAU, Vera (Org.) Linguagens, espaço e tempos no ensinar e aprender. Rio de Janeiro: DP\&A, 2000. p. 89-103.

CORREA, Bianca. Educação infantil e ensino fundamental: desafios e desencontros na implantação de uma nova política. Educação e Pesquisa, São Paulo, v. 37, n. 1, p. 105-120, abr. 2011.

DORNELLES, Leni. Os alfabetizados-desviantes ou sobre a educação dos 6 anos. Educação e Pesquisa, São Paulo, v. 37, n. 1, p. 141-155, abr. 2011.

EDWARDS, Caroline; GANDINI, Lella; FORMAN, George. As cem linguagens da criança: as abordagens de Reggio Emile. Porto Alegre: Artmed, 1999.

FERREIRO, Emilia. A representação da linguagem e o processo de alfabetização. Cadernos de Pesquisa, São Paulo, n. 52, p. 7-17, fev. 1985.

FERREIRO, Emilia. Com todas as letras. São Paulo: Cortez, 1992.

FERREIRO, Emilia; TEBEROSKY, Ana. Psicogênese da língua escrita. Porto Alegre: Artes Médicas, 1985.

FONSECA, Anita. O livro de Lili. Rio de Janeiro: Livraria Francisco Alves, 1961.

FOUCAULT, Michel. Arqueologia do saber. Petrópolis: Vozes, 1972.

FOUCAULT, Michel. Sobre a história da sexualidade. In: MACHADO, Roberto. Microfísica do poder. Rio de Janeiro: Graal, 2000a. p. 243-276.

FOUCAULT, Michel. Nietzche, a genealogia e a história. In: MACHADO, Roberto. Microfísica do poder. Rio de Janeiro: Graal, 2000b. p. 15-37.

FOUCAULT, Michel. Verdade e poder. In: MACHADO, Roberto. Microfísica do poder. Rio de Janeiro: Graal, 2000c. p. 1-14.

FRADE, Isabel. Métodos e didáticas de alfabetização: história, características e modos de fazer de professores: caderno do formador. Belo Horizonte: Ceale/FaE/UFMG, 2005. (Alfabetização e letramento).

GOUVEA, Maria. Tempos de aprender: a produção história da idade escolar. Revista Brasileira de História da Educação, Campinas, v. 8, p. 265-288, 2004.

HEYWOOD, Colin. Uma história da infância. Porto Alegre: Artes Médicas, 2005.

KATO, Mary. No mundo da escrita: uma perspectiva psicolinguística. São Paulo: Ática, 1986.

KISHIMOTO, Tizuko. Alfabetização e letramento/literacia no contexto da educação infantil: desafios para o ensino, para a pesquisa e para a formação. In: FRADE, Isabel et al. (Org.). Convergências e tensões no campo da formação e do trabalho docente. Belo Horizonte: Autêntica, 2010. p. 134-156.

KISHIMOTO, Tizuko et al. Jogo e letramento: crianças de 6 anos no ensino fundamental. Educação e Pesquisa, São Paulo, v. 37, n. 1, p. 191-210, abr. 2011.

KLEIMAN, Angela. Os significados do letramento. São Paulo: Mercado de Letras, 1995.

KRAMER, Sonia; ABRAMOVAY, Miriam. Alfabetização na pré-escola: exigência ou necessidade. Cadernos de Pesquisa, São Paulo, n. 52, p. 103-107, fev. 1985.

LEAL, Telma; SILVA, Alexsandro. Brincando, as crianças aprendem a falar e a pensar sobre a língua. In: BRANDÃO, Ana; ROSA, Ester. Ler e escrever na educação infantil: discutindo práticas pedagógicas. Belo Horizonte: Autêntica: 2010.

LEITE, Sergio. Preparando a alfabetização. São Paulo: Edicon, 1984.

LOURENÇO FILHO, Manuel. Testes ABC para a verificação da maturidade necessária à aprendizagem da leitura e da escrita. 13. ed. Brasília, DF: Inep, 2008. 
MACIEL, Francisca. Ler, escrever e contar... A história da alfabetização em Minas Gerais. In: PERES, Eliane; TAMBARA, Elomar (Org.). Livros escolares e ensino da leitura e da escrita no Brasil (séculos XIX-XX). Pelotas: Seiva, 2003. p. 11-26.

MACIEL, Francisca. Lucia Casasanta e o método global de contos: uma contribuição à história da alfabetização em Minas Gerais. 2001. Tese (Doutorado em Educação) - Universidade Federal de Minas Gerais, Belo Horizonte, 2001.

MACIEL, Francisca; LÚCIO, Iara. Os conceitos de alfabetização e letramento e os desafios da articulação entre teoria e prática. In: CASTANHEIRO, Maria; MACIEL, Francisca; MARTINS, Raquel (Org.). Alfabetização e letramento na sala de aula. Belo Horizonte: Autêntica, 2008. p. 13-34.

MALAGUZZI, Loris. Apresentação. In: EDWARDS, Carolyn; GANDINI, Lelia; FORMAN, George. As cem linguagens da criança: abordagem de Reggio Emilia na educação da primeira infância. Porto Alegre: ArtMed, 1999. p. 8-10.

MEYER, Dagmar. Abordagens pós-estruturalistas de pesquisa na interface educação, saúde e gênero: perspectiva metodológica. In: MEYER, Dagmar; PARAÍSO, Marlucy. Metodologias de pesquisas pós-críticas em educação. Belo Horizonte: Mazza, 2012. p. 47-62.

MOLL, Jacqueline. Alfabetização possível: reinventando o ensinar e o aprender. Porto Alegre: Mediação, 1996.

MORTATTI, Maria. Os sentidos da alfabetização. São Paulo: Editora Unesp, 2000.

MORTATTI, Maria. Educação e letramento. São Paulo: Editora Unesp, 2004.

MORTATTI, Maria. História dos métodos de alfabetização no Brasil: conferência de abertura. In: SEMINÁRIO ALFABETIZAÇÃO E LETRAMENTO EM DEBATE, 2006. Brasília, DF: MEC/SEB, 2006.

OLIVEIRA, Sueli. O ingresso no ensino fundamental com cinco anos: direito à escolarização ou negação do direito à infância? 2012 (Ensaio). Disponível em: <http://www.mp.rs.gov.br/ infancia/doutrina/id694.htm>. Acesso em: 30 mar. 2013.

OLIVEIRA, Maria; MONTEIRO, Conceição. Metodologia da linguagem. 4. ed. São Paulo: Saraiva, 1983.

PANSINI, Flavia; MARIN, Aline. O ingresso de crianças de 6 anos no ensino fundamental: uma pesquisa em Rondônia. Educação \& Pesquisa, São Paulo, v. 37, n. 1, p. 87-103, abr. 2011.

PARAÍSO, Marlucy. Metodologias de pesquisas pós-críticas em educação e currículo: trajetórias, pressupostos, procedimentos e estratégias analíticas. In: MEYER, Dagmar; PARAÍSO, Marlucy. Metodologias de pesquisas pós-críticas em educação. Belo Horizonte: Mazza, 2012. p. 23-46.

PARAÍSO, Marlucy. Currículo, Cultura e Diferença: “Gabriel e eu” ou “o amor é o signo”. In: COLÓQUIO SOBRE QUESTÕES CURRICULARES, 11; COLÓQUIO LUSO BRASILEIRO DE CURRÍCULO, 7; COLÓQUIO LUSO-AFRO-BRASILEIRO SOBRE QUESTÕES CURRICULARES, 1., 18 a 21 de setembro de 2014, Braga. Anais... Braga: Universidade do Minho, 2014.

PINTO, Juliana. A escolha de escolas Waldorf por famílias das camadas médias. 2009. Dissertação (Mestrado) - Universidade Federal de Minas Gerais, Belo Horizonte, 2009.

POPKEWITZ, Thomas. Pisa: números, conduta de normalização, e a alquimia das disciplinas escolares. In: FAVACHO, André; PACHECO, José; SALES, Shirlei (Org.). Currículo, conhecimento e avaliação: divergências e tensões. Curitiba: CRV, 2013. p. 89-108.

SANTOS, Lucíola; VIEIRA, Lívia. "Agora seu filho entra mais cedo na escola": a criança de seis anos no ensino fundamental de nove anos em Minas Gerais. Educação e Sociedade, Campinas, v. 27 , n. 96, p. 775-796, out. 2006.

SMOLKA, Ana. A criança na fase inicial da escrita: a alfabetização como processo discursivo. 1. ed. São Paulo: Cortez, 1988.

SOARES, Magda. Alfabetização no Brasil: o estado do conhecimento. Brasília, DF: Inep/Reduc, 1991.

SOARES, Magda. Letramento/Alfabetismo. Presença Pedagógica, Belo Horizonte, v. 2, n. 10, p. 83-89, 1996.

SOARES, Magda. Letrar é mais do que alfabetizar: entrevista. Jornal do Brasil, Rio de Janeiro, 26 nov. 2000. 
SOARES, Magda. Letramento e escolarização. In: RIBEIRO, Vera. Letramento no Brasil. São Paulo: Global, 2003a. p. 89-113.

SOARES, Magda. Letramento: um tema em três gêneros. Belo Horizonte: Autêntica, 2003b.

SOARES, Magda. Práticas de letramento e implicações para a pesquisa e para políticas de alfabetização e letramento. In: MARINHO, Marildes; CARVALHO, Gilcinei. Cultura escrita e letramento. Belo Horizonte: Editora da UFMG, 2010. p. 54-67.

SOARES, Magda; MACIEL, Francisca. Alfabetização. Brasília: MEC/Inep/Comped, 2000. (Estado do Conhecimento).

TFOUNI, Leda. Adultos não-alfabetizados: o avesso do avesso. Campinas: Pontes, 1988.

WEISZ, Telma. Apresentação. In: FERREIRO, Emilia; TEBEROSKY, Ana. Psicogênese da língua escrita. 6. ed. Porto Alegre: Artes Médicas, 1999. p. IV-XI.

WEISZ, Telma. Telma Weisz fala da alfabetização nas escolas públicas nas últimas décadas. Nova Escola. 2012. Disponível em: <http://revistaescola.abril.com.br/fundamental-1/telma-weiszfala-alfabetizacaoescolas-publicas-ultimas-decadas-683815.shtml/>. Acesso em: 30 mar. 2012.

\section{MARIA CAROLINA DA SILVA CALDEIRA}

Professora doutora da Escola de Educação Básica e Profissional, no Centro Pedagógico da Universidade Federal de Minas Gerais - UFMG -, Belo Horizonte, Minas Gerais, Brasil

mariacarolinasilva@hotmail.com

\section{MARLUCY ALVES PARAÍSO}

Professora associada do Departamento de Administração Escolar e do Programa de Pós-Graduação em Educação da Faculdade de Educação da Universidade Federal de Minas Gerais - UFMG -, Belo Horizonte, Minas Gerais, Brasil; fundadora e atual coordenadora do Grupo de Estudos e Pesquisas em Currículos e Culturas - GECC - da UFMG e Pesquisadora Produtividade 1D do Conselho Nacional de Desenvolvimento Científico e Tecnológico - CNPq marlucyparaiso@gmail.com 